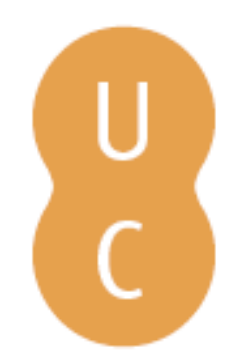

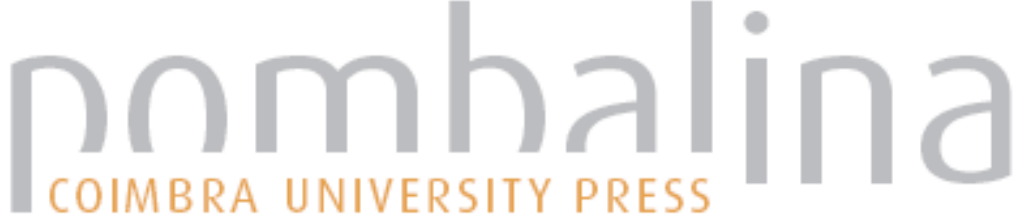

\section{Reflexões sobre arte e psiquiatria}

Autor(es): Mons Revilla, Juan

Publicado por: Imprensa da Universidade de Coimbra

URL

persistente: URI:http://hdl.handle.net/10316.2/35959

DOI: $\quad$ DOI:http://dx.doi.org/10.14195/978-989-26-0852-5_6

Accessed : $\quad$ 26-Apr-2023 00:24:14

A navegação consulta e descarregamento dos títulos inseridos nas Bibliotecas Digitais UC Digitalis, UC Pombalina e UC Impactum, pressupõem a aceitação plena e sem reservas dos Termos e Condições de Uso destas Bibliotecas Digitais, disponíveis em https://digitalis.uc.pt/pt-pt/termos.

Conforme exposto nos referidos Termos e Condições de Uso, o descarregamento de títulos de acesso restrito requer uma licença válida de autorização devendo o utilizador aceder ao(s) documento(s) a partir de um endereço de IP da instituição detentora da supramencionada licença.

Ao utilizador é apenas permitido o descarregamento para uso pessoal, pelo que o emprego do(s) título(s) descarregado(s) para outro fim, designadamente comercial, carece de autorização do respetivo autor ou editor da obra.

Na medida em que todas as obras da UC Digitalis se encontram protegidas pelo Código do Direito de Autor e Direitos Conexos e demais legislação aplicável, toda a cópia, parcial ou total, deste documento, nos casos em que é legalmente admitida, deverá conter ou fazer-se acompanhar por este aviso.

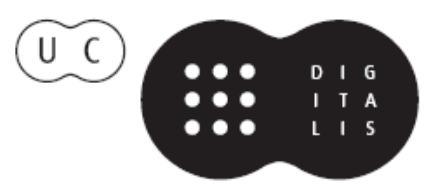



Juan Mons Revilla 1

\section{REFLEXÕ ES SOBRE ARTE E PSIQUIATRIA}

Nada aquece mais que o mau tempo

Apresentação Arte Pura

Vamos falar sobre Arte Pura

Vamos reflectir acerca da Arte em geral e sobre Diagnósticos e Terapias

Vamos falar de Génio

Vamos falar de Arte Pura como uma possibilidade de aceder ao paciente

Vamos falar sobre Terapia Expressiva ou Não-Verbal, ou Terapia pela Arte ou Plástica

Vamos falar sobre os benefícios da Criatividade e da sua História na Doença

\section{Falemos}

\section{Falemos sobre criação e arte}

Supõe-se que a criação artística seja uma projecção inevitável do "génio" que habita dentro do criador. Esta é uma frase cheia de ironia se recordarmos Marx, que disse que apenas o detalhe da produção em massa separa o parafuso e o torneiro dos museus.

De uma forma semelhante, na altura, um pintor surrealista podia começar a pintar sem quaisquer dúvidas acerca da sua estabilidade mental.

\footnotetext{
${ }^{1}$ Chefe de Serviço no Departamento de Psiquiatria do Hospital Provincial Divino Valles, Burgos. E-mail: psiquiatramons@hotmail.com
} 
E noutros tempos, Duchamp confundiu os olhos do observador e fê-lo chamar de "Fountain" (Fonte) o que era apenas, e agora continua a ser, um urinol de cerâmica.

\section{Falemos sobre génio}

Tenho dúvidas acerca do génio quando vejo artistas que continuam a exibir os seus trabalhos. Será que um génio precisa de ver as emoções que o seu trabalho desperta no observador?

\section{Falemos de espontaneidade}

Há pessoas que, vivendo num mundo próprio, dedicam o seu trabalho à Lua. Elas estão a fazer Arte Pura. Habitam a fronteira da normalidade convencional. Elas não exigem nada em troca. Criam e pintam como apenas uma criança o faria, um prisioneiro numa cadeia jurando não lá voltar, ou a vítima de um cromossoma ou um cavalo nas encruzilhadas para Damascus, inconsciente, manso de coração e em estados mentais isolados, alheios à integração social devido ao estigma. Seres que criam espontaneamente sem a expectativa de vendas ou aplausos. A FRONTEIRA que é habitada por alguns dos nossos pacientes. Mas os génios também lá estão. E as crianças. E o prisioneiro para a vida inteira.

\section{Falemos de terapia}

A chamada Terapia Expressiva, Terapia não-Verbal ou Terapia pela Arte, que é apoiada pela chamada normalidade, precisa de uma projecção interior espontânea. A disciplina de Arte foi fomentada, e repito, fomentada pelo dito mundo normal, porque concebe que, a partir desta terapia, pode ser alcançada a libertação ou uma interpretação do mundo críptico ou alarmante através da janela do inconsciente e/ou da Bio-Neuropsiquiatria.

Finalmente, uma disciplina que poderia ajudar o tratamento e/ou estabilidade do paciente, o seu melhor entendimento e/ou melhor compreensão da sua evolução e reinserção.

\section{Falemos dos terapeutas}

As pessoas que se dedicam a esta matéria devem ser profissionais, formados e assépticos, os quais não interferem ou induzem esta activi- 
dade aos pacientes, que deve ser espontânea, no caso de ocorrer. Observadores assépticos, seres de aço, guias/informadores dos momentos de "abertura" de janelas a partir da intuição, que praticam a observação e profissionalismo mudo não participante, mas orientador.

\section{Falemos sobre o porquê de estarmos a falar de arte pura}

Compreendemos que a minha ideia sobre o termo "Arte pura" diz respeito àquela que é feita de forma espontânea, sem condições pré-estabelecidas e sem procurar aplausos ou vendas. Historicamente, os denominadores comuns das obras de alguns artistas eminentes com doença mental inspiram-nos para estas reflexões. E também o facto da maioria dos seus trabalhos importantes terem sido criados nos seus períodos de tranquilidade. A questão de nós os lembrarmos como artistas e não como pacientes inspira-nos para outras reflexões.

\section{Falemos sobre o que vemos se olharmos}

Será que a obra de arte existiria sem um espectador a olhar para ela?

O trabalho artístico existe sem criação espontânea?

Uma obra existe porque alguém a criou ou porque alguém está a olhar para ela?

Será que gostamos de um trabalho devido à nossa evolução ou por persuasão exterior?

Reconhecemos o que é Arte ou é a moda que nos diz o que deve ser Arte?

A Arte Pura é arte? Não precisa a Arte Pura de ser arte de forma a ser Pura? A normalidade caminha a par e passo com o trabalho convencional de forma a estabelecer uma ponte terapêutica.

Reflectirei em torno destas questões para falar de Arte Pura, um conceito de criação espontânea. Um prisma visual que forma um corpo reflexivo desajustado relativamente àquilo que pensamos acerca de qualquer das nossas verdades e crenças presentes, aquelas que podem ser criadas por uma mentira social estratégica sempre que é repetida mil vezes. 


\section{Perspectiva social. Posse. A Imprensa e a Arte. Falemos sobre o contexto habitual}

Há poucas coisas mais desnecessárias do que o costume burguês de pendurar um quadro ou esconder uma protuberância no corredor pintando as paredes de branco. Tudo isto contém mais que uma explicação subjectiva. É verdade que o ambiente influencia o espírito, mas a posse, formando uma parte do nosso ser social, protege e torna a insegurança mais suportável ao mesmo tempo que cria um certo espírito de maior instabilidade e mais insaciável.

\section{Falemos de posse e poder}

Além do trabalho artístico, que, para que o possa ser, necessita de emoções inspiradoras, o objecto decorativo no presente foi erguido num pedestal e, à parte de ser um sinal de nível social confortável, é um sinal adolescente de poder, um estandarte pessoal e de evolução.

\section{Falemos sobre pintores reconhecidos que pintam sempre o mesmo quadro}

O nosso corredor revela, para aqueles a quem nós abrimos a porta da nossa casa, o nível de poder económico ou cultural que possuímos ou ambos em simultâneo. O burguês reconhece de olhos fechados a pintura repetida e idêntica do "reconhecido" artista. De forma similar, o visitante deixa-nos uma impressão dos nomes comerciais da camisa ou da mala que ele/ela está a usar ou um aroma distinto de bergamota deixado no corredor que reconhecemos como alheio ao nosso.

\section{Falemos dos mass media}

Mundo de eufemismo, moda de eufemismo que o Poder e os Mass Media usam. Ah, as ondas! Da sua posição de poder, os media determinam e aperfeiçoam o que é "de génio, bom e exclusivo" na sua versão moderna/ presente e mantêm-no patente com um tedioso sermão sobre "o que é bom para nós”. Morte à vossa cultura! Viva a minha cultura! Etologia. O encantador Konrad Lorenz, "mãe" dos seus gansos. Ou o drama dos 
filhos órfãos do leão derrotado e ao qual foi retirado o orgulho. O leão vitorioso mata a ninhada do leão que ele derrotou e expulsou do harém, logo formando o seu próprio orgulho. Com aquelas fêmeas cujo único caminho para o serem novamente é pararem de ser mães a amamentar os filhos do leão expulso e derrotado.

A noite escura é luz do dia para aquele que não tem nenhum critério prévio, mas quanta felicidade se ligares a luz!

A Arte Pura é aquela que nasce longe dos aplausos. Inocência brilhante, espontânea ou ousada, ela é alheia ao berço.

\section{A verdade que o tempo destila}

As coisas mudam quando o génio e aqueles que o reconheceram estão mortos e os vivos continuam a enaltecê-lo.

"Temos que esperar até que ele morra", disse um dia um rancoroso paciente a olhar para uma das minhas pinturas.

"Que permaneçam por muito tempo as tuas dúvidas e as minhas", respondi num estilo Hare Krishna.

Possuir o raro transformou muitos criadores em génios respeitados em círculos económicos.

\section{Falemos sobre o repertório}

Mas o mercado nega o acima mencionado. "Este autor custa tanto". Indubitavelmente, o custo é influenciado pelo seu valor, por clientes fiéis e por um estilo reconhecível, de forma que nós não temos que dizer a um amigo que nos visita de quem é o trabalho que possuímos, nem quanto esse objecto custou. Tudo parece indicar que o repertório funciona como refere o Professor Guimon (2008) a propósito de terapia. Provou-se que os pintores que elaboram sempre a mesma pintura são bem-sucedidos. Reconhecíveis para o burguês que habita dentro de nós.

Falemos sobre danos colaterais. Arte imposta pela rádio.

Obras aquiescentes e romanas, ambas livres e empáticas, enchem as caves dos museus. Obras boas e não tão boas são expostas ou compra- 
das, dependendo dos ciclos de prosperidade económica. A imprensa, as ondas, é a responsável por acordar aqueles que ainda não compraram e "não percebem o favor que lhes fazem".

\section{A fronteira}

Para uma pessoa saudável a integração social, a família e o trabalbo são os três pilares sobre os quais a laje em que vivemos se sustenta. Se estes pilares não forem de igual altura, similar força e desenvolvimento harmónico, a INTEGRAÇÃO, ADAPTAÇÃO, CONVENCIONALIDADE SAUDÁVEL E EQUílIBRIO tornam-se instáveis. O bem comum, a sua compreensão e aceitação, a submissão do indivíduo a ele, o seu sacrifício, subjuga o livre arbítrio e deixa a adolescência para trás. Ninguém, estando comprometido, pode continuar a sonhar consigo próprio sozinho. Acreditar - sim. Sonhar - não.

Aqueles que não aceitam ou não alcançam a compreensão do Bem Comum também vivem na FRONTEIRA e chamamos de fronteira ao TERRENO QUE LIMITA O ESTABELECIDO COMO NORMA, MAS A NORMA SERVE COMO REFERÊNCIA E NUTRIENTE.

De forma a deixar a norma, dentro e fora da fronteira, é apenas necessário abusar, dar passos USANDO A MINHA LIBERDADE E METADE DA DE OUTRA PESSOA. Não respeitar. A norma é o sal de qualquer lugar. EM CADA MERIDIANO ELA MORA NOUTRA NECESSIDADE. Isto é o porquê desta referência à norma ser necessária. Por isso, a norma não é a mesma na Terra Santa/Sem Fronteira/Normalidade e na Terra Selvagem/ Fronteira/Doença. Mas em todas elas a já mencionada regra é mantida: A tua liberdade é apenas Tua, mas não tua e metade da Minha.

Walter Chiari, um actor italiano, grita de um telhado plano àqueles que passam na rua: "Vocês são formigas.". Os transeuntes riem, porque ouvem quem lhes está gritando, mas vêem Chiari da mesma forma que ele diz que os está a ver dos vinte andares acima da rua: como uma formiga. Os transeuntes percepcionam o mesmo que Chiari.

Percepção, normas, cultura: uns estão no terraço, outros estão abaixo. 


\section{O estigma social}

\section{Vamos falar sobre o COFRE DAS LÍNGUAS}

Sobre as palavras. Sobre semântica. Sobre a Hermenêutica da Língua. Arte, na nossa cultura, é uma palavra valorizada. E Bolas também. Mas o mesmo não acontece com as palavras vagina e homossexual.

Arte é aquilo que é criado com espontaneidade e profissionalismo. Arte de Viver, de Ler e Escrever, de Falar. A Medicina é uma Arte. Pescar é uma Arte. E, também dizemos Belas Artes.

A Arte, por isso, parece fantástica. Falar sobre ela "não é aborrecimento nenhum". Eu brindo em sua honra. Será uma "grande vergonha" o que esta "rainha" está a fazer? Brindo a todos eles, homens e mulheres loucos.

Estarei a falar ardilosamente sobre o estigma e a sociedade exclusiva (?!) Porque o estigma é algo situado entre dois aspectos, pelo menos. Será o estigma vivido ou sentido, ou serão os outros que o têm e nós o conseguimos ver? Senti-lo-ia se os outros não olhassem para mim? Olharia para eles dessa forma se "eles" não fossem pacientes? Palavras avaliadas ou não. Bani-lo é o desafio entre aqueles de nós que não estão na mesma posição e têm circunstâncias, desculpas e responsabilidades atenuadas em relação àquele adolescente de "a minha liberdade é minha e metade da tua". Como é que a partir da Terra Santa/Poder/Sem Limite/Normalidade podemos roubar metade da sua liberdade para adicioná-la à nossa?

"O estigma faz com que os outros te esqueçam quando as suas vidas são boas", disse-me um paciente cheio de uma sinceridade amarga. "Mas eu faço-os valorizar a minha dignidade recuperada e estou seguro”, concluiu depois a sua confissão.

\section{Conceitos}

\section{A obra de arte}

Aceitamos um objecto como obra de arte pela surpresa emocional que a sua estrutura de conjunto produz no observador experiente. Afectou-nos. O estado induzido por ele faz-nos pensar e considerar que estamos na presença de uma Obra de Arte. 
No entanto, nem todas as pessoas conseguem apreciar o brilho de um óleo ou uma aguarela translúcida. Educação. Será que a cultura nos leva ao "choque" causado por uma instalação ${ }^{2}$ e nos faz considerá-la uma força suficiente para "mover" uma pessoa sem consciência da cultura convencional? Será que uma instalação precisa de dinheiro público que poderia ser a forma de aceitá-la, financiá-la e divulgá-la? Será esta cultura orquestrada pelo poder que administra fundos públicos? Estaremos a testemunhar o nascimento da "cultura ausente" produzida pela falta de conhecimento conscientemente programado pela escola? Será que nos estamos a aproximar de um estado que é paternalista, mas que corta a iniciativa entre as pessoas que administra? Será que temos que apelar para o "nosso" dinheiro público?

\section{Abrir a janela para o caminho da abstracção}

Consideramos uma janela um objecto feito de madeira ou alumínio numa ou noutra cor. No entanto, o que uma janela faz é emoldurar o vazio do espaço interior. Instalação, gritos, golpes, brilhos. Ground zero, cinética, dodecafonia? Chekhov, La Fura, Cervantes, Camões, Rotko, Arrabal, Bruckner, Pollock, Velazquez, Pessoa, Goya, Gordillo, Boadella, Granados, Alegria, Calderon, Duchamp e a sua fonte. Todos eles surpreenderam e nos fizeram pensar. A emoção que as suas obras ainda provocam, a franqueza da sua contemplação e o prazer antes e depois de abordar o conceito, a comparação inevitável do nosso inconsciente colectivo, ao mesmo tempo o reconhecendo mas abrindo uma nova visão na nossa memória iluminada, acerca do mesmo retrato ou paisagem conhecida, mas longe da educação recebida sobre os mesmos. A Criação por si própria torna o consenso desnecessário, mas a Criação não faz, por si própria, o génio. Será que há um génio, socialmente falando, na ausência de alguém para o proclamar? O nosso dinheiro, dinheiro público, insiste que o que um génio poderia mostrar, uma instalação por exemplo, é a novidade

\footnotetext{
${ }^{2}$ Nota do Tradutor: Installation art - género artístico caracterizado por obras tridimensionais, compostas, muitas vezes, por materiais naturais e do quotidiano, cujo objectivo é alterar a nossa percepção de um espaço.
} 
na arte, a qual ele quer divulgar e apresentar às pessoas com défice de educação humanista elementar, suportada pelo nível de educação pública e obrigatória. Eu sorrio e espero um pouco para que isso se estabeleça.

Quadro descritivo

Paisagem

Memória de Verão

Recordar a minha infância

Paisagem Casimiro Sainz
Quadro conceptual

Uma mancha espalhada sobre madeira

Memória deixada pelos pintores na minha casa

Olhar para o que um artesão deixou

Paisagem Hernandez Pijuan

Será que a Dora Maar olha de soslaio para mim? Picasso pensa tocar o céu limpo do quarto de Dora.

A janela. Contemplação do material e aquilo que é a sua essência. Vemos uma janela de madeira azul. Esquecemos que a essência da janela é o vazio que a madeira azul enquadra e não essa madeira azul. Este é o caminho sintético da Abstracção.

Os meus pacientes correm ou não. Pintam ou não. Lêem ou não. Aceitam-se ou não. Se há passividade ou pouca adesão à terapêtica, eu recomendo o hospital de dia. Aí, eles podem ser mobilizados.

\section{Espontaneidade ou indução? Arte livre ou moda}

No que diz respeito à pintura, há uma certa questão de sorte envolvida. Por acaso, alguém entre eles é iniciado na pintura "cozinha”. Por acaso, alguém fica viciado nalguma coisa. Por acaso, ele descarrega todas as suas obsessões, ansiedade ou mania em tudo aquilo que seja oferecido, criado ou feito. Nem sempre há um terapeuta especializado em cada ambiente terapêutico. Copiar, no início, serve neste caso, de forma a iniciar/manter, no ambiente específico de cada clínica, liberto quando é derramado sobre uma tela ou incorporado numa escultura. O objecto plástico resultante não tem de ser arte. É suficiente ser útil. 1975, Colónia, Alemanha. Duas instalações. Uma: tropa de cavalos a ocupar a cave de uma galeria. A outra: um ser humano, com síndrome de Down diminuído e imóvel numa cadeira é acompanhado por uma gravação de um grito penetrante 
ouvido de vez em quando. Em pouco tempo, a gravação foi levada, mas não o ser humano. E anteontem, Gerona em Espanha. Outro exemplo da hermenêutica da cultura. Um homem negro do século passado foi exposto anídrico, embalsamado, no museu de Banyolas como uma raridade na colecção dos antigos farmacêuticos. Banyolas e o seu negro do seu "Museu da Ciência”. Eles "não se aperceberam” que o "animal” exibido era um ser humano. Alemanha e Espanha. Ambas as nações depararam-se a enterrar os seus próprios velhos problemas com a desculpa da "Arte", "Taxidermia" e "Ciência”... Cultura na Alemanha e Espanha.

\section{O chamado génio na sociedade}

Vamos falar acerca do génio artístico e suas aproximações, assumindo que o génio existe até uma certa proporção em qualquer profissão. Haverá um génio sem ninguém a proclamá-lo? O génio inventa, cria em sentido transcendental. Nada daquilo que ele cria pode ser contemplado novamente sem comparar com obras de arte prévias, expostas para sempre pela nova obra do génio, num sentido que apenas relembra obras passadas se virmos algo próximo ao "discurso" criativo. Para despir o que foi previamente colocado no inconsciente colectivo. Lá não está nada...

Mas, às vezes, acontece que o criador é visto como um traidor daquilo que é artisticamente conhecido e previsível: "O que é isto?" ou, "Onde é que ele viu tal baleia?" ou, "o meu filho podia fazer isto!" e o sistema sai fora da ordem e fica dividido. Há certamente motivos de escárnio para todos...

As caves das capelas e dos museus estarão ocupadas apenas a $40 \%$ no futuro. O resto irá para a fogueira. Uma questão de tempo. Nós ouvimos "a pintura está morta”. E nós gritamos "viva a obra de arte!". Por causa de nada mais que isto, é difícil ver criação e arte a partir de "ismos". Nós somos muleteiros. Será que a arte precisa, para o ser, da emoção afectada do espectador. Precisamos de algum tipo de "génio" para agitar o observador médio, incapaz de desfrutar de uma pintura a óleo, mas capaz de ser perturbado perante uma instalação como a de Colónia na Alemanha, ou perante o que aconteceu com a senhora de meia-idade em Santander? "Pensador obediente", robot da televisão? Normalidade? 
Ingénuo. A arte é um campo de jogo pintado com as medidas de quem a produz e de quem a vende/desfruta/compra. Este território é habitado por um clima dependente, entre outros, da evolução cultural, do estado de espírito em ambos, do momento económico, de interesses alheios à própria criação, do momento cultural, das necessidades políticas, de quem regulamenta a "imprensa" escrita, vista e ouvida, de... Será tudo "glamour"? É algo para tu o dizeres e para outro o fazer. Supõe que tu ou o artista são instigados pelo poder, como verias o que ele está a criar? Será que um monge vê o mesmo que um livre-pensador? Um homem sábio e eu? Será que um céptico vê o mesmo que um esperançoso. Será que um coleccionador olha para o teu trabalho da mesma forma que a tua mãe? Vemos o mesmo a partir do berço e a partir da independência?

Será que a cultura, o seu nível, a doença, estável ou não, permitem a imaginação/criação sólida? Quase tudo foi dito sobre isto. E o que é que o nível cultural do grupo que está a olhar para a obra diz?

O génio e os heróis,

Todos grandes cultores de bílis negra ${ }^{3}$

Habitam na fronteira

(ARISTÓTELES)

\section{Criatividade na doença mental}

Akiscal e Akiscal, diz Delgado (2007), investigou estes extremos e concluiu que os pacientes Bipolar II e III apresentam um excesso de criatividade.

Mas no paciente mais grave das secções nosológicas da Bipolaridade, bem como nos pacientes com instabilidade mais rápida, esta mesma predisposição não foi observada.

\footnotetext{
3 Segundo as concepções médicas de Hipócrates e Galeno, muito influentes no tempo de Aristóteles, o predomínio de cada um dos 4 humores ou líquidos produzidos por órgãos do corpo humano (sangue, linfa, bílis amarela e bílis negra) determinava o temperamento de cada pessoa. Ao predomínio da bílis negra, segregada pelo baço, correspondia o temperamento melancólico que, segundo Aristóteles, é característico de personalidades com grandes potencialidades criadoras, quer no plano da filosofia, da arte, da política ou da poesia.
} 
No mesmo trabalho, Delgado fala sobre a influência da doença em alguns "ismos" da Arte, como o surrealismo, para o qual pessoas com esquizofrenia e internadas contribuíram de forma notável. O estudo sublinha este aspecto da evidência do sucesso de um pintor, com história clínica psiquiátrica, diferenciado e verdadeiro, entre alguns coleccionadores. Tem sido divulgado.

\section{A doença endógena e exógena. As adições}

Será que as doenças de origem endógena e/ou familiar interrompem o processo criativo, quando o paciente se sente fraco e a doença activa, excepto nos estados de perturbações bipolares acima mencionados? Parece que sim.

Um paciente que sofre de doença Bipolar anseia, em compensação, pelo seu estado hipomaníaco.

O paciente psicótico crónico, afectado por algum tipo de esquizofrenia ou por pouca adesão ao tratamento ao longo da sua evolução, normalmente deixa de criar. Contudo, as doenças mentais exógenas e, insisto, as doenças afectivas acima mencionadas, favorecem a criatividade devido à percepção exagerada, típica deste estado mental.

Numa escala mais ampla, este sofrimento "normal" também tem sido aceite como um motor para a arte. $\mathrm{O}$ mesmo acontece com o delírio omnipresente. Igualmente, salvo excepções relacionadas com grandes autores, os estados hipomaníacos excessivamente criativos não resistem a uma análise mais aprofundada em face do trabalho anterior dos que deles sofrem. Estados de "disposição maníaca", na fronteira da estabilidade emocional, fazem parte da persistência profissional necessária, de forma a produzir um trabalho sólido e solitário, que está ausente nos momentos de ritmo mais brando.

A cultura rodeia aqueles que vivem através destes estados, e as escolas psiquiátricas, em cujo contexto lhes acontece viver no seu ambiente quotidiano, ficam alarmadas ou são diagnosticadas como Escola e Local...

Claro que há excepções. Como com qualquer outra coisa. O mesmo acontece com estados induzidos por drogas, quer desencadeiem doenças mentais ou não. 
Há exemplos famosos do último, sem cuja adição e sua evolução aditiva, não teríamos parte da poesia ou pintura pelas quais os seus autores são lembrados. Poe, Toulouse, de Quincey, Artaud, Baudelaire, Rimbaud, Pollock, todos lembrados pelo que fizeram, e não por aquilo que foram. Vamos discutir isto? Não faz sentido, toda a gente teria razão.

\section{Doença e criação}

Será que podemos, por isso, estabelecer que, para a "criação", há um consenso entre as doenças "afectivas" e as endógenas, no sentido em que, entre as primeiras, há circunstâncias que a estimulam, enquanto quase todas as últimas a limitam? Para outros criadores, apreciadores de seres humanos e drogas, qual é o consenso? Poe era um génio. Mas também o eram a sua sobrinha e a sua mulher. Van Gogh foi um génio, mas também o foi Theo. Miguel Ângelo foi um génio, mas também o foi o Papa Júlio II. Arnaud foi um génio, mas também o foi o psiquiatra que lhe deu cadernos para ele escrever.

Por isso, parece que o aparecimento de psicose interfere em ambos os processos, e estes também são alterados por outras doenças exógenas, para melhor ou para pior. Compulsões, estados depressivos ou expansivos, dependências e abstinências, delírios e atitudes messiânicas, todos fazem parte do quadro sintomático e teatral em que o criador ou espectador podem ver-se imersos no momento da criação.

Será que a criação e a sua observação podem ser um teste? Como qualquer coisa, às vezes sim e outras vezes não. E, na maior parte dos casos, apenas se conheceres os pacientes ou o voyeur muito bem.

O que teria sido de Rorschach sem estatística?

Não é um facto trivial que este teste baseado em folhas com manchas de tinta possa dizer-nos algo sobre o paciente 'voyeur', tanto em termos daquilo que ele "vê" como em termos daquilo que ele "não vê" no trabalho/ folha/mancha/abstracção.

Voltando ao nosso caso: a observação e a criação são métodos dedutivos ou terapêuticos? Estará o paciente voyeur/autor "revelado" ou "entretido"? Será isto determinante? Sem conhecer o autor/observador, vamos optar 
por "entretenimento". Se os conhecêssemos, poderíamos saber mais sobre o momento que o paciente criador/doente está a atravessar.

Van Gogh (1853-1890) pintou a maior parte dos seus trabalhos nos últimos 10 anos da sua vida, repleta de insónias, absinto, rixas, noites sem dormir, auto-mutilação, infecções nosocomiais e dependências emocionais, entre outros, testemunhados e sofridos por Signac e Gauguin. Theo financiou, e o Museu Thyssen exibiu "tudo aquilo" em 2007, em Madrid.

Situação contrária foi a de Antonin Artaud (1896-1948), sofrendo da sua dupla patologia. Tarahumara (1936) e a outra, orgânica, mantêm a sua lenda e o seu desafio transgressivo através do seu drama e suas memórias. O Teatro e seu Duplo (1937), O Teatro da Crueldade (1948), as cartas de Rodez antecipam Weiss/Marat/Sade, e o próprio Maio de 1968 de Paris, com seu discurso progressivamente deteriorado, mas sempre anárquico, um motivo de reflexão entre "aquela" Norma e "esta" Norma. "Sejamos razoáveis, exijamos o impossível". Será isto um slogan da psicopatologia perversa do século XX? Reflexão anarquista? Uma exigência "ainda actual" incorporada na face desta "nova aristocracia política e administrativa"?

Lucidez. A eterna lucidez de Artaud acerca das fronteiras da consciência. A crença fervorosa em si mesmo. Egotismo adolescente em Van Gogh.

Ambos mantiveram uma criação soberba, independente das suas origens artísticas, e "furiosamente" inovadora nos seus respectivos campos.

Anteriormente, ambos tinham mostrado sinais endógenos, embora, certamente, agravados pelas suas escolhas borderline: Marginalização e Drogas.

Actividades diferentes em cada caso e, em todos os casos, intensamente experienciadas e dramaticamente frustradas. Lembremo-nos que, em ambos os casos, há uma patologia anterior à produção das obras, cuja transcendência lhes permitiu chegar até nós. Será que eles são, hoje em dia, o que são, pelo que foram? Não, actualmente eles são pelo que fizeram, derramando solidão no teatro e na pintura. 


\section{Resumo e conclusão}

ARTE PURA, ARTE MARGINAL OU ARTE BRUTA é aquela que é produzida longe do aplauso, do berço, do louvor, ou da avaliação. Arte que crianças muito jovens, as pessoas com doença mental ou presidiários (característica deste sector na sociedade, uma vez que são os únicos que sofrem longas sentenças, longe de reabilitação) são capazes de produzir.

Livres, eles produzem obras, nas quais derramam espirais psicóticas, mares de solidão e de tristeza, ou gestos de cor com modos infantis de sólidas formas primárias.

Despojados de qualquer contexto, criam uma obra espontânea. Génio! Digo como espectador, que vibra e fica excitado deste lado de uma obra que é oferecida ao olhar, ambos livres.

A qualidade da produção, a índole harmoniosa e sólida, ou a inovação que não deve nascer da representação pura de um gesto ou, às vezes, de um estado de espírito cheio de cor, são uma questão diferente.

Paciente com doença mental, presidiário, criança. Nem tudo é estimulante. Nem tudo é arte. É claro...

Dois lados para um encontro. Um paciente, livre, derrama a sua capacidade expressiva e um "outro" é abalado pela emoção provocada pela contemplação da sua obra.

\section{Utilidade da Arte pura}

Relativa. Para ser criada, analisada, apreciada.

Para o terapeuta, quanto melhor ele conhece o paciente, mais útil é o objecto criado pelo último, mais fácil é analisar o "seu" Paciente, menos enigmático é o doente. Mas lembremo-nos de que o próprio Teste de Rorschach diz tanto sobre o que o paciente vê como sobre o que ele não vê, esquece ou evita na imagem disponibilizada.

Neste teste, o referencial é fornecido por um número de manchas que permanecem sempre as mesmas. No nosso caso, para o terapeuta, o referencial é, também, a pessoa doente, e não o Paciente.

O que, no Teste de Rorschach, permanece como imagens insolúveis, no Paciente elas são o álbum fotográfico do desenvolvimento da sua 
identidade: um momento diferente, a preto e branco, consciência ou não da doença, fases, evolução da doença, diferentes fotos de identidade.

Observadores experientes, seres rigorosos, insensíveis ao ambiente, ao teste e a quem o cria, espreitando de fora da cabana, da floresta, a perspectiva interior através das janelas do edifício construído hoje no meio da neve, podem encontrar-se amanhã no meio do deserto.

É interessante analisar esta criatividade no seu contexto. Os achados coincidentes na abstracção do trabalho de um paciente conhecido podem ser úteis, podendo progressivamente ensinar-nos mais sobre ele.

De forma piramidal, a mesma observância noutro paciente com a mesma educação e denominador comum nosológico pode aproximar-nos de uma estatística do observado/ plasticidade preservada ou não. Um limite sugestivo de "normalidade", a partir da floresta. A observação da expressão na mesma pessoa quando estava doente e quando era um Paciente.

Por outro lado, a utilidade da evolução da expressão artística, no seu contexto adequado, ajuda a adesão terapêutica e a aceitação da regra de integração como parte, por exemplo, de uma terapia difícil que exige um grupo.

Será que o trabalho produzido pelo nosso paciente e pintor requer um espectador? A criação espontânea que brota da patologia que aflige a pessoa doente, bem como a explosão do génio/pintor, do inovador veterano, poderão fazer com que um crítico/coleccionador/ observador/ terapeuta experientes tomem consciência de que o que eles estão a ver não está sujeito a constrangimentos.

E um repertório previsível seria de nenhuma utilidade quer na arte para pintor, quer na terapia ocupacional para o paciente. O génio e o doente não precisam de nada. $O$ pintor e o paciente apreciam um voyeur.

\section{Insight}

O comportamento é o produto de uma multiplicidade de estados: cognitivo, afectivo, perceptivo, com propriedades não lineares, principais e adjacentes. 
O papel do insight tem como premissa as associações de ideias evocadas pela obra de arte no indivíduo ou grupos de pacientes, com as quais o terapeuta, como um "pescador", enriquece as suas interpretações.

\section{Contenda}

Capacidade para enfrentar a ansiedade do outro pela compreensão e projecção, de forma a libertá-lo da sua negatividade. Efémera ou doseada.

Balint situa no terapeuta/mãe a capacidade de detectar a dor, a solidão ou a perda que se revelam na capacidade atrofiada do seu paciente para as relações.

Ele produz de novo no paciente uma fase intermédia, transitória. A sua brevidade, despertada pela iminência da inspiração, pode ser profissionalmente impedida/ampliada ao longo do tempo, se deslocarmos pintura, escultura ou música. Outra ideia que transmite acesso ao interior é a de janela do comboio à noite, fugaz. Diz-se que depende de Empatia e Simpatia, mas Guimon (2008) argumenta que cada um de nós vê nisto o que quer. Não há uniformidade.

A assepsia experienciada, o respeito em relação ao que é visto a partir da floresta através da janela, a contenção do profissional com acesso experiente e atencioso, seres de ferro que contêm a sua intervenção, mas conseguem manter/deter/ampliar o acesso à janela fugaz do combóio rápido à noite a tempo.

\section{Processo terapêutico}

As pessoas falam de luas-de-mel. Do seu mérito para serem estendidas e disseminadas no tempo, fazendo a magia persistir, bem como do entusiasmo contido, que se mantém entre ambos os participantes.

Um espaço transitório de interacção do afectivo e do perceptivo. Do terapeuta para o paciente e vice-versa. Foulkes diz que eles melhoram a receptividade.

Os indivíduos conectam-se e comunicam entre si através de processos inconscientes, pois ambos pertencem ao mesmo rebanho, com cordas não escritas. 


\section{Referências bibliográficas}

Alonso-FernándeZ, F. (1976), Fundamentos de la Psiquiatria Actual. Tomo 1. Madrid: Editorial Paz Montalvo.

CASTILla DEL PINO (1992). Introduccion a la Psiquiatria. Alianza.

CORRONS \& AlCOCER (2006). Art-Quizofrenia. IM \& C,S.A.

Delgado Calvete (2007). Creatividad y Produccion Artistica, Psicotropias. n. ${ }^{\circ} 2$.

Diccionario de Real Academia Española (1882). Lengua.

GALIX \& MASSATS. Photographers, El Cultural, 27/6/7

Guimon, J. (2008). Locura y Pintura.

HARRISON (2008). Principios de Medicina Interna. Spain: MC Graw Hill.

LÓPEZ-IBOR ALIÑo J. J. (1975). La Psiquiatria de Hoy. Toray: Spain.

LORCA, F. G., Noche, Suite. Pessoa. Biography.

Oppenheim. Psicopatologia.

ORICO, O. (1980). Camões e Cervantes. Livraria Editora Cátedra: Rio de Janeiro. 